\title{
High origin of the deep femoral artery: a case report and literature review
}

\section{Origem alta da artéria femoral profunda: relato de caso e revisão da literatura}

Vishal Kumar ${ }^{1}$, Veerannasetty Vinay Kumar, Bukkambudhi Virupakshamurthy Murlimanju², Natanahalli Sathyanarayana Naveen³

\begin{abstract}
Arterial variations of the femoral triangle are rarely reported in the literature. In the present article, we have reported a case of high origin of the deep femoral artery, which was originating just lower to the inguinal ligament. It was also observed that the lateral circumflex femoral artery arose directly from the femoral artery instead from the deep femoral artery. We have discussed the anatomy, embryological basis, and clinical implications of these variations along with relevant literature review. The importance of knowledge about these variations in therapeutic and diagnostic interventions is discussed.
\end{abstract}

Keywords: anatomy; development; embryology; femoral artery.

\section{Resumo}

Variações arteriais no triângulo femoral têm sido pouco relatadas na literatura. No presente artigo, relatou-se um caso de origem alta da artéria femoral profunda, que estava se originando pouco abaixo do ligamento inguinal. Também foi observado que a artéria femoral circunflexa originava-se diretamente da artéria femoral, ao invés de ser originada da artéria femoral profunda. Discutiu-se sobre anatomia, base embriológica e implicações clínicas dessas variações junto com uma revisão da literatura pertinente. A importância do conhecimento sobre essas variações no quadro das intervenções diagnósticas e terapêuticas é discutida.

Palavras-chave: anatomia; desenvolvimento; embriologia; artéria femoral.

\section{Introduction}

The femoral artery (FA) is the most preferred and easily accessible to catheterization for many investigations in the present modern era of interventional radiology $y^{1}$. It is also used in several plastic and reconstructive procedures ${ }^{2}$. Accurate knowledge of the course and ramification of the vessels of the lower limbs received attention from surgeons and clinicians, due to their successful procedures in the femoral triangle 3 . Deep FA (DFA) is a large branch taking origin from the lateral part of the FA, in about $3.5 \mathrm{~cm}$ distal to the inguinal ligament (IL). It gives two branches, namely: lateral circumflex FA (LCFA) and medial circumflex FA (MCFA). The MCFA and LCFA branches anastomoses with the internal and external iliac arteries. DFA gives perforating arteries that supply the muscles of thigh and anastomoses with popliteal artery ${ }^{4,5}$. An angiogram study reported that there is normal branching pattern in $81 \%$ of cases ${ }^{6}$.

In this case, variation from the normal branching pattern of this arterial system was observed in the left femoral triangle of a male cadaver. This type of variation is reported in very few articles. The aim of this case study is to discuss the anatomy, embryological reason, and clinical significances of this abnormality along with relevant review of literature.

\section{Case report}

During the routine dissection of the lower limb of a male middle-aged cadaver, which was done for the teaching of first year medical students, it was observed that in the left femoral triangle, DFA was having a higher origin (Figure 1). It was arising at the lower border of the IL from the lateral

Study carried out at Department of Anatomy, K.S. Hegde Medical Academy, Mangalore, India

'Department of Anatomy, K.S. Hegde Medical Academy, Nitte University, Mangalore, India.

${ }^{2}$ Department of Anatomy, Kasturba Medical College, Manipal University, Mangalore, India.

${ }^{3}$ Department of Anatomy, K.M.C.T. Medical College, Calicut, India.

Financial support: none.

Conflict of interest: nothing to declare.

Submitted on: 20.08.10. Accepted on: 08.07.11.

J Vasc Bras. 2011;10(3):243-245 


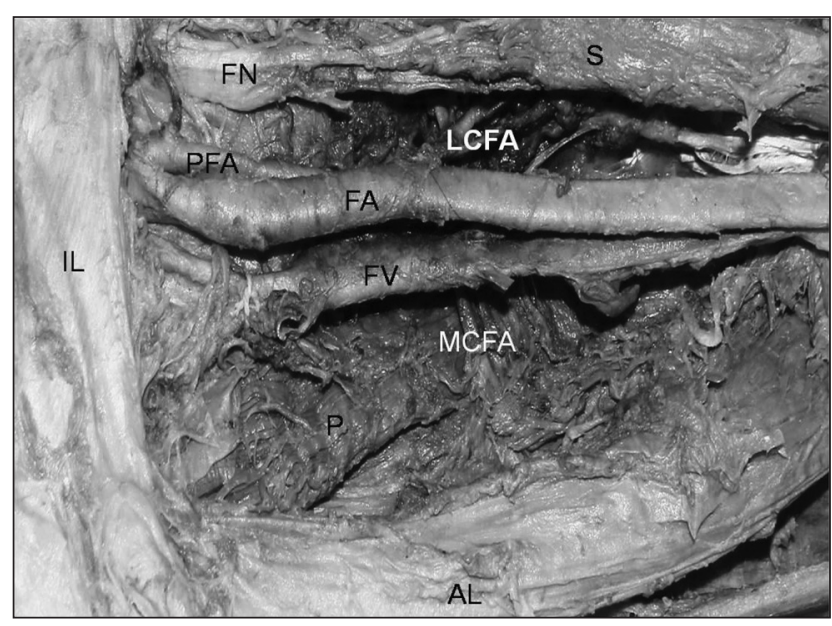

FA - femoral artery; DFA - deep femoral artery; FV- femoral vein; FN - femoral nerve; MCFAmedial circumflex femoral artery; LCFA- lateral circumflex femoral artery; AL- adductor longus; IL- inguinal ligament; $\mathrm{S}$ - sartorius; $\mathrm{P}$ - pectineus.

Figure 1. High origin of the deep femoral artery.

direction. Also, the LCFA was originating directly from the FA $5.5 \mathrm{~cm}$ distal to the origin of DFA from the posterolateral side. MCFA branched off from the DFA, $3.7 \mathrm{~cm}$ distal from the point of origin of DFA as usual. In the right femoral triangle, no such variations were observed.

\section{Discussion}

It is important to know the originating point of the DFA from the FA and one should consider the separation point as $1 \mathrm{~cm}$ above the arteriectomy incision in the embolectomy procedure done for $\mathrm{DFA}^{7}$. In most of the studies, the distance of the originating point of the DFA from the FA to the midpoint of the IL has been taken as the main criterion?

The existence of variations of the lower limb vessels can most often be explained as an abnormal development of the arterial network of the lower limb in the embryo ${ }^{1,8,9}$. FA develops from rete femorale in the ventral aspect of the thigh. It communicates with the external iliac artery above through rete pelvicum and sciatic artery below. The primary sciatic artery grows out from fifth lumbar intersegmental artery in the dorsal part of thigh, when the embryo is about $10 \mathrm{~mm}$ long and ends in plantar capillary plexus. As the development proceeds, anastomosis between the axis artery and rete femorale develops. It is generally accepted that increase of blood flow in these capillaries determines the final mature arterial pattern. Thus, the most appropriate channels enlarge while others contract and disappear ${ }^{1,8,9}$. Therefore, we can speculate that one possible reason for the observed variation in this case could be increased blood flow in the rete femorale vessels located at higher level, forming a high origin of DFA and increased blood flow in the rete femorale vessels, which are destined to form LCFA in this case.

Samarawickrama et al. ${ }^{3}$ studied 26 femoral triangles of both sides. The DFA in $46 \%$ of the cases originated from the posterior side of FA and, in $30 \%$ of the cases, from the posterolateral one. These two regions of origin have been described in the anatomy texts as the sites of the origin of the artery. However, in $23 \%$ of cases of their study, the DFA originated from the lateral aspect of the FA. In the present study, we also observed the DFA originating from the lateral aspect. When compared to site and distance of DFA origin, artery originated from the lateral side of FA when it was close to the $\mathrm{IL}^{3}$. Chitra ${ }^{10}$ reported a case in which the DFA was originating from the medial side of FA and was coursing in front of the femoral vein.

Tanyeli et al. ${ }^{11}$ observed an unusual case, in which the DFA was originating from the anterior aspect of the femoral artery, the inferior epigastric and the external pudendal arteries were arising from the DFA. They also observed that the LCFA was arising from the lateral aspect of the FA and distal to the origin of the DFA. Sahin et al. ${ }^{9}$ reported the origin of LCFA directly from the posterior surface of the FA, $4.9 \mathrm{~cm}$ below the IL.

In the present case, we also found the LCFA originating directly from the posterolateral side of FA, $5.5 \mathrm{~cm}$ distal to the IL. Shankar and Roopa ${ }^{4}$ reported a case in which DFA arose less than $1 \mathrm{~cm}$ distal to the IL. In contrast, Siddharth et al. ${ }^{12}$ found in one instance where DFA arose at the level of the IL, in the present case it was also observed that the DFA was arising at the level of IL. Dixit et al. ${ }^{13}$, in their study, reported that DFA originated mostly from the posterolateral side of the FA.

Perera ${ }^{14}$ did the study on variability in the level of DFA origin in relation to the different patterns of origin of the circumflex femoral arteries. According to his classification, in Group A MCFA and LCFA arose from the DFA. In Group $B$, either one or both femoral circumflex arteries arose from the femoral artery. He also opined that there is a distal migration of the level of DFA origin when either one or both circumflex femoral arteries arose from the femoral artery. According to Quain's data, in 7 out of 430 thighs, DFA arises at the level of IL, which is similar to our finding ${ }^{15}$. Bergman et al. ${ }^{15}$ illustrated the variations in the origin of LCFA from the FA in 26 out of 200 specimens, as in the present case. In their atlas, it was described that in 41 instances MCFA originates from the FA. In a fetal study of different gestational ages by Vuksanović-Božarić et al. ${ }^{2}$, most cases of DFA originated in the first quarter, i.e., close to the IL. A rare variation of DFA origin from a common trunk originating from external iliac artery $1 \mathrm{~cm}$ above the IL was reported by Bilgic and Sahin ${ }^{16}$. They also observed MCFA originating from the DFA and did not mention about LCFA ${ }^{16}$. 
The knowledge of the site of DFA origin is very important as it helps in avoiding iatrogenic femoral arteriovenous fistula while performing FA puncture, and it enables to identify the correct site of making incision for surgical exposure of the FA and DFA junction ${ }^{3,13}$. Shahin et al. ${ }^{9}$ opined that, before the catheterization of femoral vessels and operations in the femoral triangle, high-resolution ultrasonic imaging can provide anatomic and functional information about the femoral vessels and would be of assistance in planning catheterization ${ }^{9}$. Shankar and Roopa ${ }^{4}$ reported that high origin of DFA can cause problem in procedures like femoral arterial and venous puncture and femoral nerve blocks, because of close relationship of vessels and nerve in femoral triangle ${ }^{4}$. Pseudoaneurysms can occur when the puncture site is the DFA or FA distal to the origin of the DFA. This usually happens when there is lack of knowledge of these variations ${ }^{17}$. The direction of the origin of DFA is also important in catheter application, in making flaps with pedicles, in reconstructive surgery and bypass procedures made to supply the lower extremity ${ }^{7}$. The diameter of DFA decreases as the site of its origin becomes more distal from the $\mathrm{IL}^{2}$. It was also described that this knowledge is very useful in preventing the necrosis of flap, when used in plastic and reconstructive surger $y^{2}$. The DFA is very useful in lower limb revascularization procedures done for non-healing ulcers and/or gangrene, to relieve the claudication pain ${ }^{18}$.

We conclude that if the surgeon is unaware of these variations, the surgical procedure around this area can lead to disaster during therapeutic and diagnostic procedures. The sound knowledge about the anatomical variations of femoral vessels and their branches in the femoral triangle is very important for the successful outcome. We believe that this report is of importance to the general and vascular surgeons and will enlighten them to avoid the unnecessary complication. This study is also informative for the anatomists and morphologists.

\section{References}

1. Prakash, Kumari J, Bhardwaj AK, Jose BA, Yadav SK, Singh G. Variations in the origins of the profunda femoris, medial and lateral femoral circumflex arteries: a cadaveric study in the Indian population. Rom J Morphol Embryol. 2010;51:167-70.

2. Vuksanović-Božarić A, Stefanović N, Pavlović S, Đurašković R, Ranđelović J. Analysis of deep femoral artery origin variances on fetal material. Facta universitatis. Series: Med Biol. 2007;14:112-6.

3. Samarawickrama MB, Nanayakkara BG, Wimalagunarathna KW, Nishantha DG, Walawage UB. Branching pattern of the femoral artery at the femoral triangle: a cadaver study. Galle Med J. 2009; $14: 31-4$
4. Shankar N, Roopa R. Unusual bilateral origins of the deep artery of thigh and associated variations. International Journal of Anatomical Variations. 2009;2:99-101.

5. Standring S. Gray's Anatomy. 39th ed. Edinburgh: Elsevier; 2005. p. $1450-2$.

6. Massoud TF, Fletcher EW. Anatomical variants of the profunda femoris artery: an angiographic study. Surg Radiol Anat. 1997;19:99-103.

7. Sabancıoğulları V, Koşar MI, Ölçü E, Çimen M. The deep femoral artery and branching variations: a case report. Cumhuriyet Med J. 2009;31:279-82.

8. Çiftcioglu E, Kale A, Kopuz C, Edizer M, Aydln E, Demir MT. Medial circumflex femoral artery with different origin and course: a case report and review of the literature. Folia Morphol. 2009;68:188-91.

9. Sahin B, Uzun A, Emirzeoglu M, Kosif R, Bilgic S. A deep femoral artery passing in front of the femoral vein. Folia Morphol. 2003;62:143-6.

10. Chitra R. A rare variational anatomy of the profunda femoris artery. Folia Morphol (Warsz). 2008;67:157-8.

11. Tanyeli E, Yildirim M, Uzel M, Vural F. Deep femoral artery with four variations: a case report. Surg Radiol Anat. 2006;28:211-3.

12. Siddarth P, Smith NL, Mason RA, Giron F. Variational anatomy of the deep femoral artery. Anat Rec.1985;212:206-9.

13. Dixit DP, Mehta LA, Kothari ML. Variations in the origin and course of profunda femoris artery. I Anat Soc India. 2001;50:6-7.

14. Perera J. Anatomy of the origin of the deep femoral artery. Ceylon Med J. 1995;40:139-41.

15. Bergman AR, Afifi KA, Miyauchi R. Variation in Deep Femoral (Profunda Femoris) Artery. Illustrated Encyclopedia of Human Anatomy Variation: Opus II: Cardiovascular System. [cited 2011 may 27]. Available at www.anatomyatlases.org.

16. Bilgic S, Sahin S. Rare arterial variation: a common trunk from external iliac artery for the obturator, inferior epigastric and profunda femoris arteries. Surg Radiol Anat. 1997;19:45-7.

17. Baptist M, Hussain T, Sultana F. The origin of profunda femoris artery, its branches and diameter of the femoral artery. Professional Med J. 2007;14:523-7.

18. Natale A, Belcastro M, Palleschi A, Baldi I. The mid-distal deep femoral artery: few important centimeters in vascular surgery. Ann Vasc Surg. 2007;21:111-6.

Correspondence Vishal Kumar Department of Anatomy, K.S. Hegde Medical Academy Deralakatte, Mangalore - 575018, India E-mail:vishalanat@gmail.com

Author's contribution Conception and design: VK Analysis and interpretation: VK, NSN Data collection: NSN, VK Writing the article: VK, BVM Critical revision of the article: BVM Final approval of the article*: VK, BVM Statistical analysis: NSN Overall responsibility: VK ${ }^{*}$ All authors have read and aproved the final version of the article submitted on J Vasc Bras. 